\title{
Verification and intercomparison of reactive transport codes to describe root-uptake
}

\section{Journal Article}

\section{Author(s):}

Nowack, B.; Mayer, K.U.; Oswald, S.E.; van Beinum, W.; Appelo, C.A.J.; Jacques, D.; Seuntjens, P.; Gérard, F.; Jaillard, B.; Schnepf, A.; Roose, T.

\section{Publication date:}

2006

\section{Permanent link:}

https://doi.org/10.3929/ethz-b-000024929

\section{Rights / license:}

In Copyright - Non-Commercial Use Permitted

Originally published in:

Plant and Soil 285(1-2), https://doi.org/10.1007/s11104-006-9017-3 


\title{
Verification and intercomparison of reactive transport codes to describe root-uptake
}

\author{
B. Nowack - K. U. Mayer - S. E. Oswald • \\ W. van Beinum - C. A. J. Appelo - D. Jacques • \\ P. Seuntjens $\cdot$ F. Gérard · B. Jaillard \\ A. Schnepf · T. Roose
}

Received: 8 November 2005/ Accepted: 14 April 2006/Published online: 14 July 2006

(C) Springer Science+Business Media B.V. 2006

\begin{abstract}
Several mathematical models have been developed to simulate processes and interactions in the plant rhizosphere. Most of these models are based on a rather simplified description of the soil chemistry and interactions of plant roots in the rhizosphere. In particular the feedback loops between exudation, water and solute uptake are mostly not considered, although their importance in the bioavailability of mineral elements for plants has been demonstrated. The aim of this work was to evaluate three existing
\end{abstract}

\section{B. Nowack $(\bowtie)$}

Institute of Terrestrial Ecology, ETH Zurich,

Universitaetstrasse 16, 8092 Zurich, Switzerland

e-mail: nowack@env.ethz.ch

\section{K. U. Mayer}

Department of Earth and Ocean Sciences, University of British Columbia, V6T 1Z4 Vancouver, British

Columbia, Canada

S. E. Oswald

Department of Hydrogeology (HDG), UFZ Centre for Environmental Research Leipzig-Halle GmbH,

04318 Leipzig, Germany

\section{W. van Beinum}

Central Science Laboratory, Sand Hutton, York

YO41 1LZ, UK

C. A. J. Appelo

Hydrochemical Consultant, Valeriusstraat 11,

NL 1071 MB Amsterdam, The Netherlands coupled speciation-transport tools to model rhizosphere processes. In the field of hydrogeochemistry, such computational tools have been developed to describe acid-base and redox reactions, complexation and ion exchange, adsorption and precipitation of chemical species in soils and aquifers using thermodynamic and kinetic relationships. We implemented and tested a simple rhizosphere model with three geochemical computational tools (ORCHESTRA, MIN3P, and PHREEQC). The first step was an accuracy

\author{
D. Jacques \\ Performance Assessment Section, \\ Waste \& Disposal Department, \\ SCK*CEN, Boeretang 200, B-2400 Mol \\ Belgium \\ P. Seuntjens \\ Vito, Flemish Institute for Technological Research, \\ Boeretang 200, B-2400 Mol, Belgium \\ F. Gérard \\ Unité Biogéochimie des Ecosystèmes Forestiers, \\ Institut National de Recherche Agronomique, \\ F-54280 Champenoux, France \\ B. Jaillard \\ UMR INRA-ENSA.M Rhizosphère \& Symbiose, \\ Institut National de Recherche Agronomique, \\ 34060 Montpellier cedex 2, France
}


analysis of the different solution strategies by comparing the numerical results to the analytical solution of solute uptake ( $\mathrm{K}$ or $\mathrm{Ca}$ ) by a single cylindrical root. All models are able to reproduce the concentration profiles as well as the uptake flux. The relative error of the simulated concentration profile decreases with increasing distance from the root. The uptake flux was simulated for all codes with less than $5 \%$ error for $\mathrm{K}$ and less than $0.4 \%$ for $\mathrm{Ca}$. The strength of the codes presented in this paper is that they can also be used to investigate more complex and coupled biogeochemical processes in rhizosphere models. This is shown exemplarily with simulations involving both exudation and uptake and the simultaneous uptake of solute and water.

Keywords Modeling - Root uptake Single root · Numerical simulation - Analytical solution ·

Transport

\section{Introduction}

The rhizosphere is by definition the environment around plant roots. It is thus characterized by considerable microbial biomass, accelerated rates of water, nutrient, and contaminant flows, as well as chemical and biochemical reactions driven by plant-induced input of energy. Hence, located at the interface between plant roots and soil, the rhizosphere is the focal point of plant-soilmicrobe interactions and represents a unique biogeochemical reactor. Therefore, it is crucial to improve the understanding of the fundamental processes involved in order to better optimize the performance of this reactor.

However, even though rhizosphere research has had a relatively long tradition, going back to

\footnotetext{
A. Schnepf

Department of Forest and Soil Sciences, University of Natural Resources and Applied Life Sciences, BOKU, A-1180 Vienna, Austria

\section{T. Roose}

Centre for Mathematical Biology and Oxford Centre for Industrial and Applied Mathematics,

Mathematical Institute, 24-29 St Giles, Oxford OX1 3LB, UK
}

Hiltner in 1904 (Hiltner 1904), our understanding of rhizosphere processes is still limited. More qualitative and quantitative assessment and modeling of rhizosphere processes with emphasis on rhizosphere-bulk soil interactions is required to provide tools for proper management of these processes in phytotechnologies, including management of plant nutrition and health in sustainable farming, forestry systems and ecological engineering, such as phytoremediation, phytoamelioration and phytoprevention.

Uptake of chemicals by the plant root system depends mainly on three sets of factors. These are (i) physical factors such as geometry, morphology and diffusion properties of the soil around roots and (ii) biological factors such as symbiotic status of the root system, rate of growth, uptake and exudation by roots, and (iii) chemical factors such as the initial distribution and speciation of chemical elements in the soil, including adsorption, complexation, acid-base and redox reactions between elements dissolved in the pore water and soil minerals.

Several mathematical models have been developed to simulate these interactions in the plant rhizosphere (Barber 1995; Tinker and Nye 2000). However, most of these models are based on a rather simplified description of the soil chemistry and interactions of plant roots in the rhizosphere. For example, the actions exerted by roots on its rhizosphere are generally limited to elemental uptake, and the chemical interactions between dissolved elements and the soil are reduced to a buffer power or Freundlich adsorption isotherms (Barber 1995; Kirk 1999). In particular the feedback loops between exudation, soil and element uptake are not considered, although many authors have demonstrated their importance in the bioavailability of mineral elements for plants (Parker and Pedler 1997).

The chemical and biological actions exerted by roots in the rhizosphere are mainly changes in element concentrations, $\mathrm{pH}$ and Eh shifts, and exudation of organic anions or enzymes. These actions change the chemical conditions in the rhizosphere, affect the bioavailability of mineral elements and therefore their uptake by roots. Some root uptake models have been specifically developed to incorporate speciation calculations and reactions of mineral elements or organic 
exudates with soil. Examples include modeling the effect of citrate exudation on phosphate uptake (Geelhoed et al. 1999), of proton on aluminum speciation in the rhizosphere (Calba et al. 1999, 2004) and of ligands on copper uptake by roots (Seuntjens et al. 2004). However, these models are very specialized because they are designed to answer specific questions. Consequently, they can neither easily be extended to include other processes or additional interactions nor to test a large range of processes.

In hydrogeochemistry, sophisticated computational models have been developed to describe acid-base and redox reactions, complexation and ion exchange, adsorption, dissolution and precipitation of chemical species in soil environments using thermodynamic and kinetic relationships. Examples of such computer codes are MINEQL (Westall et al. 1972) and MINTEQA2 (Allison et al. 1991). Others such as PHREEQC (Parkhurst and Appelo 1999), ECOSAT (Keizer and van Riemsdijk 1995) and ORCHESTRA (Meeussen 2003) have been extended to combine these geochemical processes with transport calculations. Additionally there are computer codes that are specialized in modeling three-dimensional transport in variably saturated media that include geo-chemical modeling. MIN3P (Mayer et al. 2002) is an example of such a code. An application of these models allows us in principle to describe root nutrient uptake and exudation of organic acids in the rhizosphere therefore enabling us to model complex and multiple interactions between roots and soil.

The recent coupling of PHREEQC to HYDRUS-1D (Simunek et al. 1998) resulting in HP1 (Jacques and Simunek 2005) allows considering root growth and water uptake in 1D flow problems under natural boundary conditions (precipitation, evapotranspiration) in conjunction with geochemical speciation, equilibrium and kinetic reactions. An example of such coupled processes under steady-state flow conditions was already given (Seuntjens et al. 2004). So far, HP1 has not been used to model these coupled processes for natural vegetation conditions.

The general aim of this work is to evaluate existing modeling tools, recognized and accepted by the scientific community, in their capability to model rhizosphere processes. To do so, we implemented and tested a simple rhizosphere model with these computational modeling tools. The aim of this paper is to assess the accuracy of the different approaches that were used to implement a cylindrical root in these coupled speciation-transport models. The uptake of $\mathrm{K}$ or $\mathrm{Ca}$ into a single root was simulated using three codes, ORCHESTRA (Meeussen 2003), PHREEQC (Parkhurst and Appelo 1999) and MIN3P (Mayer et al. 2002) for the same set of parameters. By comparison of the numerical results to an existing analytical solution of solute uptake by a single root (Roose et al. 2001) the trustworthiness of these approaches was assessed. In addition we also extended the simple model by including water flow towards the root and water uptake. We also present an extension of the model where exudation of citrate and interaction of citrate and phosphate is included. The description of the implementation of root uptake will be useful for researchers working on rhizosphere-soil interactions and will provide them with direct access to current modeling capabilities for transport and chemical processes, now also applicable to the rhizosphere.

\section{Material and methods}

Description and aim of the case studies

ORCHESTRA is a computational modeling framework developed by Meeussen (2003) for modeling equilibrium chemistry, with the option of including kinetics and/or transport processes. The package is distinctive in that all model definitions are separate from the calculation engine or equation solver. This separation has the advantage that the model definitions are fully accessible by the user, which gives flexibility in the adaptation of the model structure and equations. ORCHESTRA is object-oriented and model definitions are stored as object classes in the object database. New models can be built using model definitions from the object database, or by adjustment or addition of model definitions if required. The object database contains basic geochemical reactions such as complexation in 
solution, ionic strength correction, minerals, gases, different types of sorption, redox reactions, kinetic reactions, as well as more advanced sorption models that account for $\mathrm{pH}$-dependent sorption and electrostatic interactions.

PHREEQC (Parkhurst and Appelo 1999) is a computer code to simulate a large number of geochemical reactions in water and geological media. Geochemical reactions include interactions between aqueous phase, minerals, gases, solid solutions, exchangers, and surface complexation for both equilibrium, kinetic or mixed equilibriumkinetic reactions. Furthermore, PHREEQC solves the one-dimensional reactive transport equation using a mixing cell solution approach (or central finite difference scheme, see Appelo and Postma (2005), for details). The non-iterative sequential approach is used to solve the coupled reactive transport problem, meaning that the transport step (solute diffusion) and the reaction step (adsorption and kinetic uptake of solutes at the root surface) are split within every time step.

MIN3P can simulate one- to three-dimensional flow and reactive transport problems in variably saturated media. The flow solution is based on Richard's equation and transport of solute is simulated using the standard advection-dispersion equation, while gas transport in the unsaturated zone is assumed purely diffusive (Mayer et al. 2002). Geochemical processes considered are aqueous complexation, mineral dissolutionprecipitation, intra-aqueous kinetic reactions, gas dissolution, ion exchange, surface complexation, and linear sorption. Transport can take place in both the gas and aqueous phases. This allows the simulation of the ingress of atmospheric $\mathrm{O}_{2}$ and permits considering soils as systems that are semiopen to the atmosphere $\left(\mathrm{CO}_{2}\right.$ balance between gas, aqueous and solid phase). Similar to PHREEQC, reactions are specified through a database. The solution of the governing equations is based on the global implicit method (GIM), in which the reaction equations are directly substituted into the transport equations, known as the direct substitution approach (DSA) (Yeh and Tripathi 1989). Spatial discretization is performed using block centered finite differences with halfcells on the boundary. The code provides a choice of various spatial weighting schemes for advective transport (upstream, centered, Van Leer flux limiter) and uses implicit time weighting. Although the numerical accuracy of implicit time weighting is limited for many problem types, it is unconditionally stable (Unger and Forsyth 1996) and has the advantage that it facilitates large time steps under certain conditions. The grid spacing, model parameters and boundary conditions can be varied in zones of rectangular shape in each direction, i.e., also for a single cell if desired. Specific to applications in the rhizosphere, recent model developments enable MIN3P to consider root water uptake and preferential water flow in a 1D unsaturated soil profile, as shown by modeling soil moisture variations measured in a forest ecosystem (Gérard et al. 2004).

The strength of the codes used in this paper is that it is relatively straightforward to consider more complex and coupled biogeochemical processes in rhizosphere models. The three codes all have a main strength. ORCHESTRA is the most flexible code because the model definitions are fully accessible by the user, which gives flexibility in the adaptation of the model structure and equations. Both ORCHESTRA and PHREEQC are more versatile for geochemical modeling. However PHREEQC is easier to use because the models are readily available in the user-interface and PHREEQC has large number of users in geochemistry and environmental chemistry. Although not quite as comprehensive as PHREEQC from a geochemical point of view, MIN3P is also capable of simulating reaction networks including equilibrium and kinetic reactions. The main strength of the MIN3P code is that it can tackle complex one-, two-, and three-dimensional scenarios under variably saturated conditions. Specifically, the simulation of unsaturated flow and transport can be considered simultaneously with geochemical reactions.

The three codes have been used to simulate the diffusion and uptake of solutes towards a single root for a specified set of parameters. The results are compared to the analytical solution of this scenario. As examples we have chosen uptake of $\mathrm{K}$, which is present at rather low concentrations in the soil solution and is taken up with fast kinetics and $\mathrm{Ca}$, which is present at elevated concentrations and is taken up at a much lower rate. 
Analytical solution of uptake into a single root

The simplest model for nutrient uptake by a root is described in Roose et al. (2001). This model is based on previous models (Tinker and Nye 2000; Barber 1995). Roose et al. (2001) use dimensional analysis and asymptotic approximation techniques to derive an analytic expression for nutrient uptake by a single cylindrical root in unbounded soil. Here we will briefly outline the main elements of the Roose et al. (2001) approach.

The nutrient concentration $c\left(\mathrm{~mol} \mathrm{~m}^{-3}\right)$ in the soil water phase is given by

$$
(\phi+b) \frac{\partial c}{\partial r}-\frac{a V}{r} \frac{\partial c}{\partial r}=\frac{\phi D f}{r} \frac{\partial}{\partial r}\left(r \frac{\partial c}{\partial r}\right)
$$

where $\phi$ is the soil water content $\left(\mathrm{m}^{3} \mathrm{~m}^{-3}\right), b=$ $c_{\mathrm{s}} / c$ is the soil buffer power (where $c_{\mathrm{s}}$ is the concentration of solute bound to the soil particles $\left(\mathrm{mol} \mathrm{m}^{-3}\right)$, Tinker and Nye 2000), $b$ is dimensionless and valid only for linear sorption), $a$ is the radius of the root $(\mathrm{m}), V$ is the volume of water flowing into the root through the unit area of root in unit time $\left(\mathrm{m}^{3} \mathrm{~m}^{-2} \mathrm{~s}^{-1}=\mathrm{m} \mathrm{s}^{-1}\right), D$ is the nutrient diffusion coefficient in water $\left(\mathrm{m}^{2} \mathrm{~s}^{-1}\right), f$ is the nutrient diffusion impedance factor (dimensionless), also known as tortuosity, $r$ is the radial distance from the centre of the root $(\mathrm{m})$, and $t$ is the time (s).

In order to solve this equation one has to define the boundary condition. The first boundary condition describes the nutrient uptake at the root surface $r=a$, and it assumes that the flux of nutrient into the root is given by MichaelisMenten nutrient uptake law, i.e.,

$\phi D f \frac{\partial c}{\partial r}+V c=\frac{F_{\mathrm{m}} c}{K_{\mathrm{m}}+c} \quad$ at $r=a$,

where $F_{\mathrm{m}}\left(\mathrm{mol} \mathrm{m}^{-2} \mathrm{~s}^{-1}\right)$ and $K_{\mathrm{m}}\left(\mathrm{mol} \mathrm{m}^{-3}\right)$ are the Michaelis-Menten nutrient uptake parameters.

Very far away from the root we assume that the nutrient concentration is undisturbed by the presence of the root nutrient uptake, i.e., we take

$c \rightarrow c_{0}$ as $r \rightarrow \infty$, where $c_{0}\left(\mathrm{~mol} \mathrm{~m}^{-3}\right)$ is the concentration of nutrient in the soil in absence of the root system.

In addition to these boundary conditions, we also need an initial condition that we specify at a constant nutrient concentration, i.e.,

$c=c_{0}$ at $t=0$ and $a \leq r<\infty$.

Roose et al. (2001) non-dimensionalized these equations and found the leading order analytical solution using matched asymptotic analysis tools. An important observation from the non-dimensionalization was that diffusion is the dominant mechanism for the nutrient movement to the root surface since the Peclet number is small, i.e., $P e=V a /(\phi \mathrm{fD})<<1$ and therefore the advection term in the equations can be neglected. For the specific case of $\mathrm{P}$ uptake (Roose, 2000), the water flux $V$ into the root would have to be much larger than $4.5 \times 10^{-}$ ${ }^{5} \mathrm{~cm} \mathrm{~s}^{-1}$ for advective solute uptake to be important (typical recorded flux values in Barber 1995, and Tinker and Nye 2000 are on the order of $10^{-7} \mathrm{~cm} \mathrm{~s}^{-1}$, so the water uptake would need to increase by about 100 times before advection becomes even comparable to diffusion). This value is clearly outside the standard value recorded for most plants. However, if the reader is interested in the case when advection is important we want to highlight the issue that the numerical solution of equations which do include advection and diffusion terms is more difficult than numerical solution of a diffusion equation. Therefore great care should be taken when doing this. Such analytical solutions are presented for example in Roose (2000).

In order to derive the equation, Roose et al. (2001) used matched asymptotic expansions in space (Hinch 1991), and therefore the solutions derived were valid everywhere in the space domain, i.e., they are valid for $a<r<\infty$. Furthermore, they are valid for times larger than diffusional timescale of the nutrient calculated using the root radius as length scale, i.e., they are valid for times $t>(\phi+\mathrm{b}) \mathrm{a}^{2} /(\phi \mathrm{D})$. For most nutrients in most soils this means that the solutions are valid for times more than a few minutes to at most a day depending on a nutrient and soil 
considered. Thus, the solutions derived by Roose et al. (2001) are valid for all times that are in the order of the root growth time-scale which typically ranges from weeks to months. Readers that are interested in specific mathematical techniques are referred to the original paper (Roose et al. 2001).

Thus, the Roose et al. (2001) solutions to the rate of nutrient uptake $F(t)$ as a function of time $t$ and the concentration profile $c(r, t)$ of the nutrient around the root are given by

$$
\begin{aligned}
F(t)= & \frac{2 F_{\mathrm{m}} c_{\infty}}{1+c_{\infty}+L(t)+\sqrt{4 c_{\infty}+\left[1-c_{\infty}+L(t)\right]^{2}}} \\
c(r, t)= & c_{0}-\frac{2 c_{0} \lambda}{1+c_{\infty}+L(t)+\sqrt{4 c_{\infty}+\left[1-c_{\infty}+L(t)\right]^{2}}} \\
& \times E_{1}\left(\frac{(\phi+b) r^{2}}{\phi D} \frac{r^{2}}{4 t}\right)
\end{aligned}
$$

where

$$
\begin{aligned}
& c_{\infty}=c_{0} / K_{\mathrm{m}}, \\
& \lambda=F_{\mathrm{m}} a /\left(\phi D f K_{\mathrm{m}}\right), \\
& E_{1}(x)=\int_{x}^{\infty} \frac{\mathrm{e}^{-y}}{y} \mathrm{~d} y, \\
& L(t)=\frac{\lambda}{2} \ln \left(4 \mathrm{e}^{-\gamma} \frac{\phi D}{(\phi+b) a^{2}} t+1\right)
\end{aligned}
$$

and $\gamma=0.5772$ is Euler's constant. In equation (6) the last equation represents a standard definition of exponential integral function where $y$ is the integration variable and $x$ is the value of the parameter where the function is evaluated.

The analytical solutions given by Eqs. 5 and 6 will now be used as a guideline for determining if the computational soil speciation models can describe root nutrient uptake with sufficient accuracy. Tests are performed for $\mathrm{Ca}-$ and K-uptake with the parameters given in Table 1 . The water flow towards the root is zero so there is no advection.

\section{Procedure ORCHESTRA}

The rhizosphere diffusion model was implemented in ORCHESTRA as a finite-difference numerical scheme with discrete calculation cells. Diffusion towards the root is assumed symmetrical and can therefore be solved as a one-dimensional problem. Radial diffusion towards the root is calculated in a one-dimensional grid of calculation cells, with one cell representing the root and 50 cells representing concentric layers of soil around the root (see Fig. 1). Diffusion is simulated by mass transfer between the 50 soil cells, and uptake by the plant root is calculated between the innermost soil cell and the root cell. Diffusion and uptake are calculated with a non-iterative sequential approach using small and constant time steps ( $\mathrm{d} t=10^{-3}$ days). The time step needs to be small enough to avoid numerical instability.

The diffusion flux between two adjacent soil cells is calculated with

$F_{\mathrm{D}, i j}(t \rightarrow t+\Delta t)=-\phi D f \frac{c(j, t)-c(i, t)}{h_{i j}}$

where $F_{\mathrm{D}, i j}(t \rightarrow \mathrm{t}+\Delta t)$ is the diffusion flux between cell $i$ and $j$ during the period from $t$ until $t+\Delta t, c(j, t)$ is the concentration in solution in cell $j$ at time $t, h_{i j}$ is the distance between the centres of cell $i$ and $j, \phi$ is the water content of the soil, $D$ is the diffusion coefficient in water and $f$ is the tortuosity correction factor. The flux then needs to be multiplied by the time step $(\Delta t)$ and the interfacial area between the cells $\left(A_{i j}\right)$ to obtain the amount of chemical $(m)$ that is transported from one cell to another. The flux for uptake by the root is calculated using the Michaelis-Menten equation:

$F_{\mathrm{U}}(t \rightarrow t+\Delta t)=\frac{F_{\mathrm{m}} c(1, t)}{K_{\mathrm{m}}+c(1, t)}$

where $F_{\mathrm{U}}(t \rightarrow \mathrm{t}+\Delta t)$ is the uptake flux from cell 1 into cell 0 (the root cell) during the period from $t$ until $t+\Delta t, c(1, t)$ is the concentration in cell 1 at time $t$, and $F_{\mathrm{m}}$ and $K_{\mathrm{m}}$ are the Michaelis-Menten parameters. The flux then needs to be multiplied by the time step $(\Delta t)$ and the surface area $(A)$ between the cells to obtain the amount of chemical $(m)$ that is transported from cell 1 into cell 0 .

The amount of chemical that leaves or enters a cell during a time step due to diffusion or uptake is added up for each cell. Then after each time 
Table 1 Input parameters to describe K and Ca uptake (from Roose et al. 2001, except where noted)

\begin{tabular}{|c|c|c|c|c|c|}
\hline Parameter & Symbol & Unit & $\mathrm{K}$ & & $\mathrm{Ca}$ \\
\hline Root radius & $a$ & $\mathrm{~cm}$ & & 0.02 & \\
\hline Water content & $\phi$ & - & & 0.3 & \\
\hline Diffusion coefficient & $D$ & $\mathrm{~cm}^{2} \mathrm{~s}^{-1}$ & & $1.0 \times 10^{-5}$ & \\
\hline Effective diffusion coefficient $\left(^{*}\right)$ & $D_{\text {eff }}$ & $\mathrm{cm}^{2} \mathrm{~s}^{-1}$ & & $3.0 \times 10^{-6}$ & \\
\hline Apparent diffusion coefficient (\#) & $D_{\mathrm{a}}$ & $\mathrm{cm}^{2} \mathrm{~s}^{-1}$ & $2.29 \times 10^{-8}$ & & $5.76 \times 10^{-9}$ \\
\hline Impedance factor & $F$ & - & & 0.3 & \\
\hline Water flux to root & $V$ & & & 0 & \\
\hline Initial concentration & $C_{0}$ & $\mu \mathrm{mol} \mathrm{cm}{ }^{-3}$ & $4.6 \times 10^{-2}$ & & $8.0 \times 10^{-1}$ \\
\hline Buffer capacity & $B$ & - & 39 & & 156 \\
\hline Retardation coefficient $(*)$ & $R$ & - & 131 & & 521 \\
\hline Michaelis-Menten & $F_{\mathrm{m}}$ & $\mu \mathrm{mol} \mathrm{cm}{ }^{-2} \mathrm{~s}^{-1}$ & $3 \times 10^{-5}$ & & $8.9 \times 10^{-7 a}$ \\
\hline Michaelis-Menten & $K_{\mathrm{m}}$ & $\mu \mathrm{mol} \mathrm{cm}{ }^{-3}$ & 0.014 & & $0.3^{\mathrm{b}}$ \\
\hline Effective rate coefficient (*) & $k_{\mathrm{m}}$ & $\mu \mathrm{mol} \mathrm{cm} \mathrm{c}^{-3} \mathrm{~s}^{-1}$ & $2.356 \times 10^{-3}$ & & $6.99 \times 10^{-5}$ \\
\hline
\end{tabular}

Parameters in italics are specific to MIN3P (*) or PHREEQC (\#)

${ }^{\mathrm{a}}$ From Silberbush et al. (2005)

${ }^{\mathrm{b}}$ From Barber (1995)
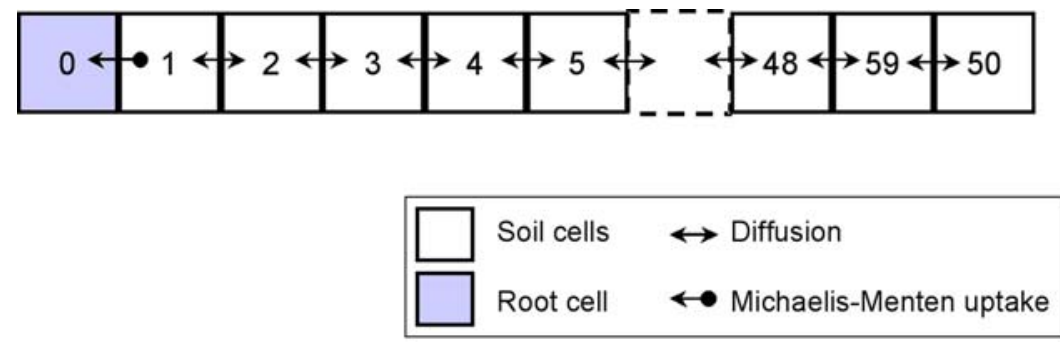

Fig. 1 Schematic representation of the diffusion model in ORCHESTRA. Radial diffusion and uptake by the root is

step, the new amount of chemical in each cell is calculated subject to conservation of mass. The resulting mass change per cell due to diffusion only (cell 2-50) is given by:

$$
\begin{aligned}
& \frac{m(j, t+\Delta t)-m(j, t)}{\Delta t} \\
& \quad=\phi D f \sum_{i \neq j}^{n} \frac{A_{i j}}{h_{i j}}(c(i, t)-c(j, t)) \quad \text { for } j>1 ;
\end{aligned}
$$

where $m(j, t)$ is the amount of chemical in the $j$ th cell at time $t, \Delta t$ is the time step, $i$ is an adjacent cell and $n$ is the number of adjacent cells. $A_{i j}$ is the cylindrical surface area between cell $i$ and cell $j$ and $h_{i j}$ is the distance between the centers of cell $i$ and cell $j$. The resulting changes in mass in the root cell $(j=0)$ and the first soil cell $(j=1)$ are described by solved by mass transfer between the soil cells (cells 1-50) representing concentric soil layers around the root, and Michaelis-Menten uptake into the root cell (cell 0)

$$
\begin{aligned}
& \frac{m(j, t+\Delta t)-m(j, t)}{\Delta t} \\
& =A_{0} \frac{F_{\mathrm{m}} c(j+1, t)}{K_{\mathrm{m}}+c(j+1, t)} \quad \text { for } j=0 ; \\
& \frac{m(j, t+\Delta t)-m(j, t)}{\Delta t} \\
& =\phi D f \sum_{i \neq j}^{n}\left(\frac{A_{i j}}{h_{i j}}(c(i, t)-c(j, t))\right) \\
& -A_{0} \frac{F_{\mathrm{m}} c(j, t)}{K_{\mathrm{m}}+c(j, t)} \quad \text { for } j=1 ;
\end{aligned}
$$

where $F_{\mathrm{m}}$ and $K_{\mathrm{m}}$ are the Michaelis-Menten uptake parameters and $A_{0}$ is the surface area of the root. After each transport calculation, the new equilibrium concentrations are calculated from the total amount of a chemical in a cell. The total mass in the $j$ th cell is given by: 
$m=V_{j}(\phi c+\rho K c)$

in which $V_{j}$ is the total volume of the cell, $\rho$ the density and $K$ is the linear sorption coefficient. The latter relates to the buffer capacity by

$$
K=\frac{\phi}{\rho} b
$$

ORCHESTRA uses a Newton-Raphson iteration procedure to solve the equilibrium sorption and solution concentrations. In this case sorption of $\mathrm{Ca}$ and $\mathrm{K}$ is a linear relationship that could be solved without iteration. However chemical sorption is more often a non-linear multi-component process for which iteration is a much more effective and versatile method. The uptake and diffusion of $\mathrm{K}$ and $\mathrm{Ca}$ were solved simultaneously in ORCHESTRA. Chemicals would need to be simulated simultaneously if they would interact, for example by co-dissolution or competition for sorption.

To improve accuracy of the numerical solution, the thickness of the soil layers was varied with the distance from the root. The layers are thinner closer to the root where the concentration gradient is expected to be high. The radius of every cell is calculated in the model by

outer radius cell

$$
=\text { width soil profile } \cdot\left(\frac{\mathrm{n}}{\mathrm{N}}\right)^{2}+\text { radius root }
$$

in which $n$ is the cell number (1-50 counted from the root surface), and $N$ is the total number of cells $(N=50)$. The volume of every concentric layer, and the diffusion distance and area between the layers, are calculated from this radius.

\section{Procedure PHREEQC}

To model the radial diffusion of nutrients towards a single root, the option of diffusion within a series of stagnant zones is used (see p. 51 in Parkhurst and Appelo 1999). The stagnant zone is overlaid by a finite difference grid to solve Fick's diffusion equation

$$
\begin{aligned}
& \frac{c(j, t+\Delta t)-c(j, t)}{\Delta t} \\
& =D f \sum_{i \neq j}^{n} \frac{A_{i j}}{h_{i j} V_{j}}(c(i, t)-c(j, t)) f_{b c}
\end{aligned}
$$

where $c(j, t)$ is the concentration in the $j$ th cell at time $t\left(\mathrm{~mol} \mathrm{l}^{-1}\right), \Delta t$ is the time step (s), $i$ is an adjacent cell, $n$ is the number of adjacent cells $(=2$ in this problem), $A_{i j}$ is the surface area between the $i$ th and $j$ th cell $\left(\mathrm{m}^{2}\right), h_{i j}$ is the distance between the midpoints of the $i$ th and $j$ th cell $(\mathrm{m}), V_{j}$ is the volume of the cell $\left(\mathrm{m}^{3}\right)$, and $f_{b c}$ is 1 for all cells except when in contact with the constant soil solution and the root for which $f_{b c}$ is 2 for a constant concentration at the boundary (Appelo and Postma 2005). By adapting the volumes $V_{j}$ and the surface areas $A_{i j}$, radial diffusion can be described. Equation (15) can be reformulated in terms of mixing factors as

$c(j, t+\Delta t)=\operatorname{mixf}_{j j} c(j, t)+\sum_{i \neq j}^{n} \operatorname{mixf}_{i j} c(i, t)$

with

$$
\begin{aligned}
\operatorname{mixf}_{i j} & =\frac{D f \Delta t A_{i j} f_{b c}}{h_{i j} V_{j}} \\
\operatorname{mixf}_{j j} & =1-D f \Delta t \sum_{i \neq j}^{n} \frac{A_{i j} f_{b c}}{h_{i j} V_{j}}
\end{aligned}
$$

To prevent numerical oscillations, the value of mixf should be between 0 and 1 . In principle, a grid with equal $h_{i j}$ 's yields second order accuracy of the calculations, i.e. refining the grid by a factor of 2 will increases the accuracy of the results by a factor of 4. PHREEQC allows to model sorption by (non-specific) ion exchange and by (specific) surface complexation reactions. The latter can be used to implement linear equilibrium sorption. The linear adsorption isotherm is redefined in terms of the size of the surface. For the reaction $\mathrm{K}^{+}+S=S \mathrm{~K}^{+}$(with $S$ the sorption surface), the relation between the equilibrium constant $K$ of this reactions and the buffer power $b$ is 


$$
K=\frac{b \phi}{S}
$$

where $S$ is the amount of free sorption sites. To have a constant value of $K, S$ is taken very large compared to the sites covered with $\mathrm{K}^{+}$(e.g., $S=10^{100}$ moles). Alternatively the diffusion coefficient, $D$, in Eqs. 1, 5 and 6 can be replaced by an apparent diffusion coefficient $D_{\text {a }}$ defined as

$D_{\mathrm{a}}=\frac{D f}{R}=\frac{D f}{(1+b / \phi)}$

where $R$ is the retardation coefficient. This approach is adapted here, because larger time steps $\Delta t$ are possible with a smaller $D_{\text {a }}$ (Eq. 17). The reported computation time in the next sections are related to this second approach in which diffusion and uptake for $\mathrm{K}$ and $\mathrm{Ca}$ were separately simulated. When modeling real multicomponentmultispecies rhizosphere problems, the first approach should be used resulting in an increase of the computational time.

The uptake of $\mathrm{K}$ and $\mathrm{Ca}$ described by Michaelis-Menten kinetics is included as an irreversible kinetic reaction in the first cell (representing the root). By implementing a smaller flux with the apparent diffusion coefficient $D_{\mathrm{e}}$ the rate parameter in the MichaelisMenten equation, $F_{\mathrm{m}}$, must be reduced by dividing by $R$ (see Eq. 2). The user-defined kinetic reaction is written in Basic language in the input file. PHREEQC integrates the kinetic rates with the Runge-Kutta method or with a stiff-equation solver. When the maximal rate of root solute uptake is so high that diffusion through the soil is rate-limiting, the concentration of the solute becomes zero at the root surface. In our case, the fast rate of $\mathrm{K}^{+}$uptake results in a zero concentration, which can be mimicked in PHREEQC (and other geochemical models) by imposing an equilibrium reaction with a very small equilibrium concentration (e.g., $10^{-15} \mathrm{~mol} \mathrm{l}^{-1}$ ). Initial calculations has shown that this approach gives equal results to the kinetic approach for $\mathrm{K}^{+}$(results not shown). This approach speeds up the calculation times significantly.
Procedure MIN3P

MIN3P provides a general solution of the advection-dispersion equation coupled with nonlinear geochemical reactions. In this case, we use a subset of these equations by only considering diffusive transport in the aqueous phase subject to a linear sorption isotherm and an uptake term in the root cell. Spatial discretization is performed using the block centered finite difference method, yielding similar discretized equations as described for ORCHESTRA (Eqs. 9-11) and PHREEQC (Eq. 16). MIN3P uses implicit time weighting, which allows the code to take relatively large time steps for the example considered here. For a detailed description of the governing equations and solution methods employed, we refer the interested reader to Mayer et al. (2002).

Since the one-dimensional set-up in MIN3P is not designed to represent a radial transport regime (of cylindrical or spherical symmetry), a two-dimensional set-up was used to simulate transport to the root. Thus, a quarter section of a plane perpendicular to the root was simulated, with the root represented at one corner and the sides extending sufficiently far to maintain background concentration values at the desired time scale, therefore approximating an infinite boundary (Fig. 2).

For this two-dimensional representation, a suitable geometry for describing the root had to be determined. The root is represented by a number of cells extending from 0.015 to $0.025 \mathrm{~cm}$, with the center of the cell located at $0.02 \mathrm{~cm}$, therefore crudely mimicking a quarter-circle (Fig. 2). In total, the base case model consisted of $57 \times 57$ cells, having a vertical extension of $1 \mathrm{~m}$, which constitutes the net root length. The time steps were adjusted automatically by MIN3P with a maximum time step of 1.0 day used in the base case simulation.

Some parameters used in the analytical model had to be converted to be consistent with the MIN3P formulation. Rate coefficients in MIN3P are defined on a per volume basis. A rate expression similar to Eq. 8 is used to calculate the effective root uptake rate $F_{M}^{\prime}$ per volume for each grid cell: 
Fig. 2 Schematic representation of the discretization in MIN3P. Diffusion and uptake by the root is simulated in a 2D domain. Symmetry of the problem allows to simplify the domain to one quarter of the full domain. The inset shows the location of the root cells (grey-shaded area)

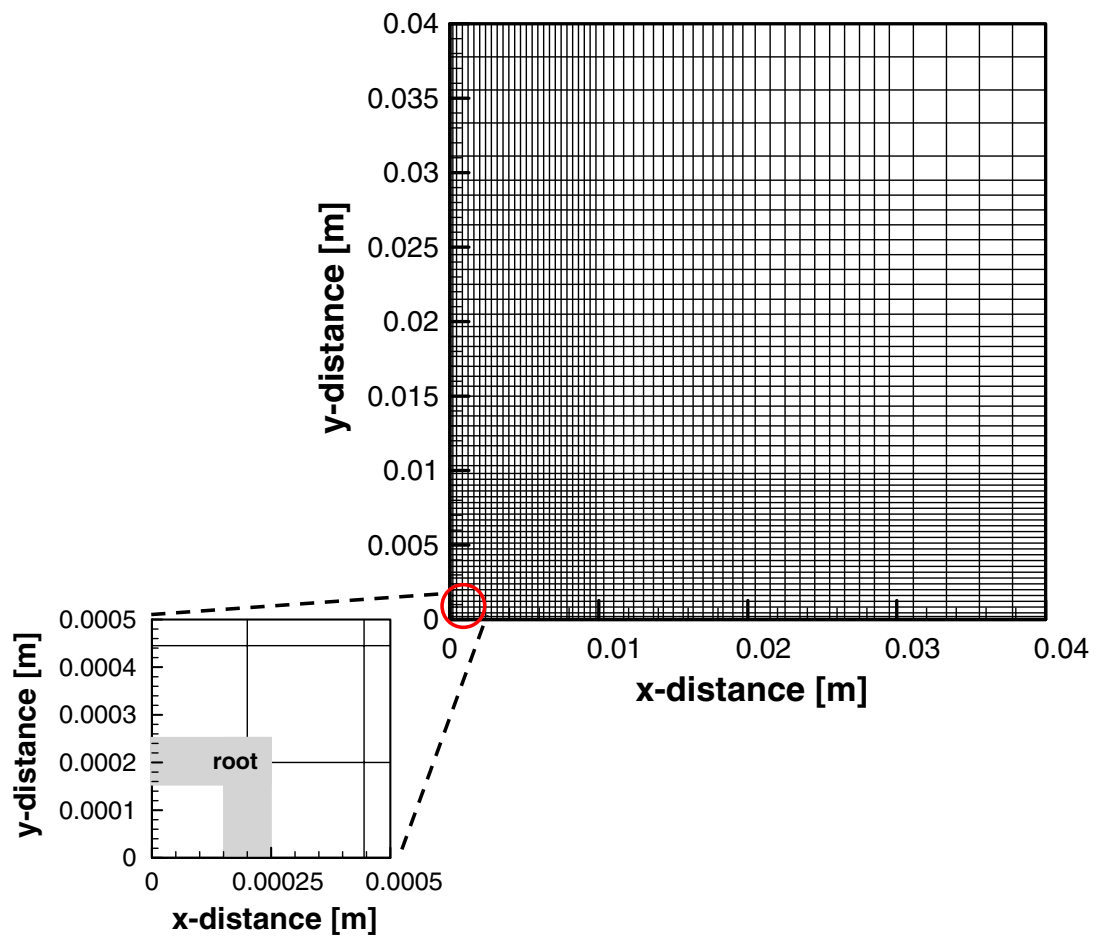

$F_{\mathrm{M}}^{\prime}=\frac{k_{\mathrm{m}} c}{K_{\mathrm{m}}+c}$

where $k_{\mathrm{m}}$ is defined in units of $\mu \mathrm{mol} \mathrm{cm} \mathrm{cm}^{-3} \mathrm{~s}^{-1}$ on a volume basis instead of the surface basis of the Michaelis-Menten nutrient uptake parameter $F_{\mathrm{m}}$. The rate coefficient $k_{\mathrm{m}}$ can be calculated from the parameter $F_{\mathrm{m}}$ by:

$k_{\mathrm{m}}=\left(A_{\mathrm{r}} F_{\mathrm{m}}\right) / V_{\mathrm{r}}$

where $A_{\mathrm{r}}$ is the root surface, notably for a quarter circle, and $V_{\mathrm{r}}$ corresponds to the total volume of all root cells in the MIN3P simulations (cf. Fig. 2). The rate coefficients used in MIN3P are $2.356 \times 10^{-3} \mu \mathrm{mol} \mathrm{cm}{ }^{-3} \mathrm{~s}^{-1}$ and $6.990 \times 10^{-5} \mu \mathrm{mol} \mathrm{cm}{ }^{-3} \mathrm{~s}^{-1}$ for $\mathrm{K}$ and $\mathrm{Ca}$, respectively. The total uptake rate at each time is evaluated in MIN3P by multiplying the $F_{M}^{\prime}$ of each root cell with its volume and summation over all root cells.

The retardation coefficient used in MIN3P is related to the buffer capacity and porosity through $R=1+b / \phi$. The resulting values for the retardation coefficient are $131(\mathrm{~K})$ and $521(\mathrm{Ca})$. This approach was chosen because it is a simple, fixed distribution between the species sorbed at the solid phase and the ones remaining in aqueous phase, and thus is able to represent the buffer capacity as required. Notably, MIN3P is capable also of explicitly handling ion exchange reactions as well as sorption via surface sites and according reactions, but this features were not needed for the current study.

MIN3P allows calculating the tortuosity (impedance factor) $f$ as a function of porosity or alternatively allows to use an effective diffusion coefficient $D_{\text {eff }}$, defined by the product of $D$ and $f$. For consistency with the other simulations, the second option was used here. Furthermore, $\mathrm{Cl}^{-}$ was added for maintaining charge balance, although this is not a necessary requirement to run the code. Thus, the simulations calculate $\mathrm{K}^{+}, \mathrm{Ca}^{2+}$ and $\mathrm{Cl}^{-}$transport simultaneously.

\section{Numerical setup}

All parameters used for the simulation are given in Table 1. The simulations were performed for a constant water content of 0.3 under saturated conditions. The accuracy of the model output was tested by repeating model runs (i) varying the 
number of calculation cells, and (ii) varying the length of the time step. An accurate numerical solution is assumed if the output does not change notably when the model resolution is increased.

ORCHESTRA produces output concentrations for the centre of each calculation cell. For the model validation we selected 16 locations at $0.1,0.2, \ldots, 1.0,1.25,1.5,1.75,2,2.5$, and $3 \mathrm{~cm}$. The concentrations at these locations were calculated by linear interpolation of the ORCHESTRA output.

In principle, the discretization scheme used in PHREEQC is similar to that of ORCHESTRA, i.e. a number of cells discretized in radial dimensions, each having a volume and surface area depending on the distance from the root centre. The size of the cells, $r_{\mathrm{f}}$, is not described by Eq. 14, but, to obtain second order accuracy, the distance between cell-midpoints is made equal where the concentration gradient changes markedly. The spatial discretization scheme consists of a regular fine discretisation between the root surface and $1.62 \mathrm{~cm}$ and a raw discretization between 1.62 and $4.00 \mathrm{~cm}$ consisting of five $0.476 \mathrm{~cm}$-width cells. The cell width $\Delta r_{\mathrm{f}}$ at the root surface determines the number of cells in the simulation (e.g., if $\Delta r_{\mathrm{f}}=2.0 \times 10^{-2} \mathrm{~cm}, 87$ cells are needed). For the model validation we selected 16 locations at $0.1,0.2, \ldots, 1,1.25,1.5$, $1.75,2,2.5$, and $3 \mathrm{~cm}$.

\section{Model evaluation measures}

The accuracy of the concentration profiles was quantified as proposed by Steefel and MacQuarrie (1996), normalised for the initial concentration $\left(c_{0}\right)$ in the model:

$$
\|x\|_{2}=\frac{\sqrt{\sum_{i=1}^{N_{x}} x_{i}^{2}}}{N_{x} \cdot c_{0}}
$$

where $x$ is the vector of concentration differences between the numerical and analytical solution at a given location in the domain, $N_{x}$ the number of locations used and $c_{0}$ the initial concentration. The accuracy of the root solute uptake flux $E_{\mathrm{F}}$ was calculated as

$$
E_{\mathrm{F}}=100 \frac{F_{\text {Code }}-F_{\text {analytical }}}{F_{\text {analytical }}}
$$

where $F_{\text {Code }}$ and $F_{\text {analytical }}$ are the root solute uptake flux after $120 \mathrm{~d}$ obtained with the three codes and the analytical solution, respectively. Thus, $E_{\mathrm{F}}$ gives the relative error in total root uptake expressed as a percentage of the root uptake calculated analytically.

\section{Additional simulations}

As an example to illustrate further possibilities of the presented codes, we extended the rhizosphere model in ORCHESTRA to simulate phosphate uptake and citrate exudation by a root, as described by Geelhoed et al. (1999). In this example, phosphate is bound to an iron-oxide mineral (goethite) in a sand matrix. The plant root takes up phosphate actively from the soil solution, which causes phosphate diffusion towards the root. The phosphate concentration directly at the root surface is assumed zero in the model because of the active uptake by the root (zero-sink). Citrate exudation from the root promotes the uptake of phosphate. Citrate competes for binding on the same mineral surface, therefore part of the phosphate is released into the soil solution. Geelhoed et al. (1999) used the CD-MUSIC model (Hiemstra and Van Riemsdijk 1996) to describe the surface chemistry of goethite. The CD-MUSIC model is available in the ORCHESTRA database. We included it in the rhizosphere model above, along with the solution speciation of phosphate and citrate. The parameters for root radius, soil density, soil water content, diffusion coefficients and tortuosity were adjusted to the values given in Geelhoed et al. (1999) and convection towards the root $\left(0.21 \mathrm{~mm} \mathrm{day}^{-1}\right)$ was introduced. The calculations were performed for $95 \mathrm{~m}^{2}$ goethite per $\mathrm{kg}$ sand, $1.9 \mu \mathrm{mol} \mathrm{m}{ }^{-2}$ phosphate initially bound on the goethite surface, $0.5 \mu \mathrm{mol} \mathrm{m}{ }^{-1}$ day $^{-1}$ citrate exudation and $t=1$ day. The initial concentration of citrate in the soil was zero and the $\mathrm{pH}$ is constant at $\mathrm{pH} 5$.

In all previous model calculations, water flux to the root was neglected to simplify the calculations. 
An additional example using the standard version of MIN3P is presented where water flux towards the root is taken into consideration. Thus, the uptake of $\mathrm{Ca}$ as defined in Table 1 is simulated together with a concurrent water uptake of $10^{-6} \mathrm{~cm}^{3} \mathrm{~cm}^{-2} \mathrm{~s}^{-1}$ (Barber 1995), corresponding to $10^{-3} 1 \mathrm{~m}^{-1} \mathrm{~d}^{-1}$ for the root dimensions that we have used.

\section{Results}

Concentration profiles

Figures 3 and 4 show the concentrations of $\mathrm{K}$ and $\mathrm{Ca}$ in the rhizosphere after 120 days of uptake by the root. Figures $3 \mathrm{a}$ and $4 \mathrm{a}$ show the direct comparison of the different models with the analytical solution. Almost no difference between
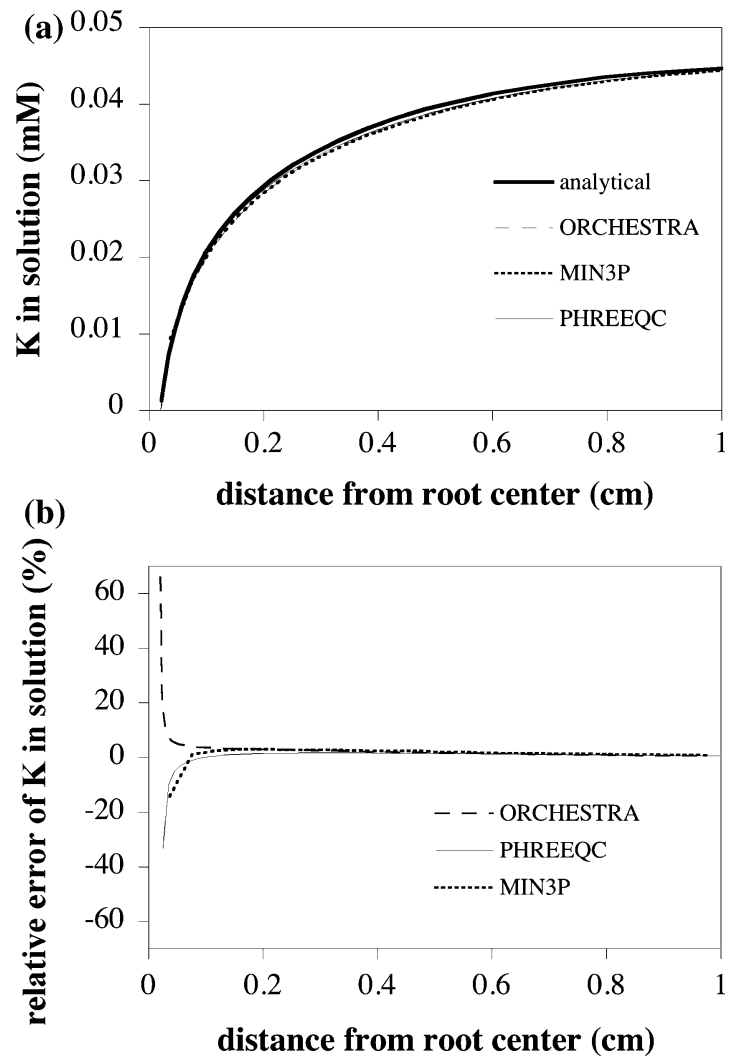

Fig. $3 \mathrm{~K}$ concentration in soil solution after 120 days. Comparison of the analytical solution, the ORCHESTRA, MIN3P and PHREEQC simulation. (a) Concentration profile, (b) error relative to the analytical solution. The parameters for the calculations are given in Table 1

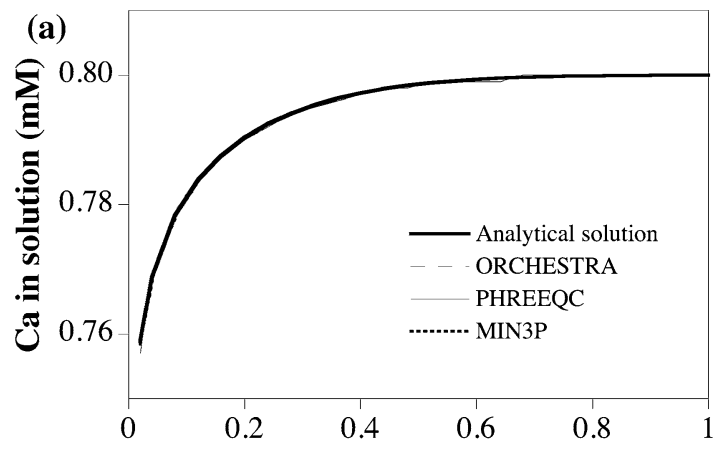

(b)

distance from root center $(\mathrm{cm})$

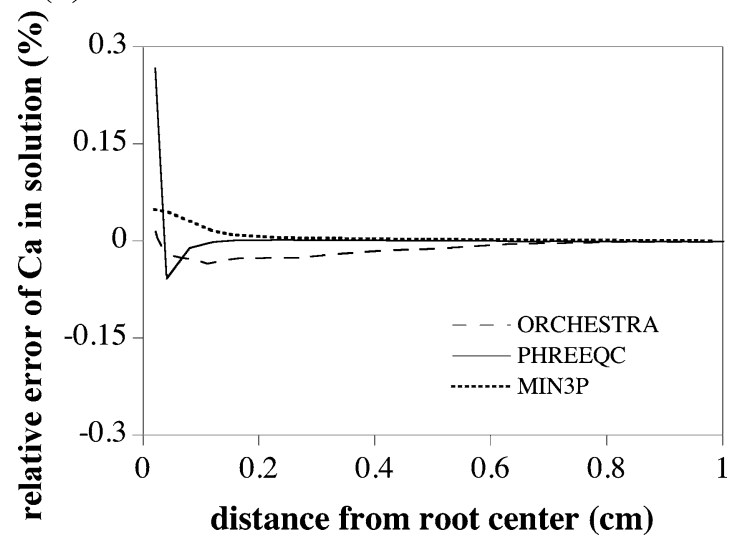

Fig. $4 \mathrm{Ca}$ concentration in soil solution after 120 days. Comparison of the analytical solution, the ORCHESTRA, MIN3P and PHREEQC simulation. (a) Concentration profile, (b) error relative to the analytical solution. The parameters for the calculations are given in Table 1

the analytical solution and the model simulations can be seen. The relative errors (Fig. 3b, 4b) are consequently small for the three models and over- or underestimation at short distance from the root does not impair correct prediction at greater distance. The relative error for $\mathrm{K}$ at $0.05 \mathrm{~cm}$ is $5 \%$ for ORCHESTRA and PHREEQC and $10 \%$ for MIN3P. Already at $0.1 \mathrm{~cm}$ it is between 0 and $4 \%$ for the three models. An overor underestimation of the concentration of $\mathrm{K}$ by $10-60 \%$ occurs at very small distance (less than $0.04 \mathrm{~cm}$ from the root center), that is essentially in the very first cell outside the root cell(s) in the model. The relative error for $\mathrm{Ca}$ is always less than $0.3 \%$ even in close proximity to the root. The accuracy measure $\|x\|_{2}$ (see Eq. 22) of the profiles is given in Tables 2-4. Overall the accuracy is very good with a relative error of $\mathrm{K}$ between 0.001 and 0.002 for MIN3P, about 0.003 
Table 2 Accuracy and efficiency measures for ORCHESTRA

simulations

${ }^{\mathrm{a}}$ On a Pentium(R) 4, $3.00 \mathrm{GHz}$; simultaneous simulation of $\mathrm{K}$ and $\mathrm{Ca}$

\begin{tabular}{|c|c|c|c|c|c|c|c|}
\hline & \multirow{2}{*}{$\begin{array}{l}\text { Number of } \\
\text { cells }\end{array}$} & \multirow{2}{*}{$\begin{array}{l}\Delta t \\
\text { (days) }\end{array}$} & \multirow{2}{*}{$\begin{array}{l}\text { Simulation } \\
\text { time }(s)^{\mathrm{a}}\end{array}$} & $\|x\|_{2}$ & $E_{\mathrm{F}}$ & $\|x\|_{2}$ & $E_{\mathrm{F}}$ \\
\hline & & & & \multicolumn{2}{|l|}{$\mathrm{K}$} & \multicolumn{2}{|l|}{$\mathrm{Ca}$} \\
\hline Base case & 50 & $1 \times 10^{-3}$ & 195 & $2.8 \times 10^{-3}$ & -2.9 & $2.2 \times 10^{-5}$ & 0.017 \\
\hline Reduced $\Delta t$ & 50 & $5 \times 10^{-4}$ & 427 & $2.8 \times 10^{-3}$ & -2.9 & $2.2 \times 10^{-5}$ & 0.017 \\
\hline Coarse grid & 25 & $5 \times 10^{-3}$ & 20 & $3.2 \times 10^{-3}$ & -1.4 & $3.6 \times 10^{-5}$ & 0.051 \\
\hline Fine grid & 100 & $2 \times 10^{-4}$ & 1883 & $2.8 \times 10^{-3}$ & -3.3 & $7.9 \times 10^{-6}$ & 0.004 \\
\hline
\end{tabular}

for ORCHESTRA and 0.03-0.06 for PHREEQC. The relative error for $\mathrm{Ca}$ is much smaller with values between $7.9 \times 10^{-6}$ and $2.16 \times 10^{-4}$.

The concentration plots for ORCHESTRA provide a good resolution of the steep $\mathrm{K}$ gradient near the root, since the dimension of the numerical cells was varied with distance from the root. Despite the small time steps of $10^{-3}$ days, the simulation required only a few minutes. For ORCHESTRA the accuracy of the numerical solution with 50 cells and $10^{-3}$ day time steps was tested by repeating the calculations with half and twice the number of cells, and with twice the number of time steps (half $\mathrm{d} t$ ). As expected, the simulation time increased significantly with the number of calculation cells, see Table 2, though the results of the simulations were very similar. The test shows that a model with 50 cells and time steps of $10^{-3}$ days is sufficient for the model calculations presented here.

The root uptake of $\mathrm{K}$ is fast compared to diffusion of $\mathrm{K}$ through the soil and therefore, $\mathrm{K}$ uptake can be described by equilibrium reactions in PHREEQC. The equilibrium approach gives identical K-concentration profiles after $120 \mathrm{~d}$ compared to the kinetic approach (for $\left.\Delta r_{\mathrm{f}}=2.0 \times 10^{-4} \mathrm{~m}\right)$. However, the calculation time of the latter is much longer than the former:
$125 \mathrm{~s}$ compared to $29 \mathrm{~s}$ (on a Pentium(R) 4, $3.06 \mathrm{GHz}$ computer). Table 3 reports the accuracy measures for four spatial discretisations for PHREEQC. For $\Delta r_{\mathrm{f}}=4.0 \times 10^{-2} \mathrm{~cm}$ and smaller, concentration profiles are similar and close to analytical solution. Ca concentration profiles are accurately described for $\Delta r_{\mathrm{f}}$ discretisations of at least $4.0 \times 10^{-2} \mathrm{~cm}$.

Simulations results using the MIN3P code provide solutions of similar accuracy for $\mathrm{Ca}-$ and K-concentration profiles. Although the twodimensional discretization leads to a significantly larger number of nodes (equal to 3249) in comparison to the other codes that use a onedimensional representation $(50$ and 87 for ORCHESTRA and PHREEQC, respectively), the computational demand was comparable although MIN3P was run using a slower processor (257 sec for the base case simulation on a Pentium(R) 2, $700 \mathrm{MHz}$ ). This is due to the fact that MIN3P simulations were conducted with adaptive time stepping starting with a minimum time step of $10^{-10}$ days and maxing out at a time step of 1 day (for the base case). This approach allowed completing the base case simulation using a total of 150 time steps. Using time steps of this magnitude was possible due to the use of the global implicit method and implicit time
Table 3 Accuracy and efficiency measures for PHREEQC simulations

${ }^{\mathrm{a}}$ On a Pentium(R) 4, $3.06 \mathrm{GHz}$

\begin{tabular}{|c|c|c|c|c|c|c|c|c|}
\hline & \multirow{2}{*}{$\begin{array}{l}\text { Number } \\
\text { of cells }\end{array}$} & \multirow{2}{*}{$\begin{array}{l}\Delta t \\
\text { (days) }\end{array}$} & \multirow{2}{*}{$\begin{array}{l}\Delta r_{\mathrm{f}} \\
(\mathrm{cm})\end{array}$} & \multirow{2}{*}{$\begin{array}{l}\text { Simulation } \\
\text { time }(s)^{\mathrm{a}}\end{array}$} & $\|x\|_{2}$ & $E_{F}$ & $\|x\|_{2}$ & $E_{\mathrm{F}}$ \\
\hline & & & & & \multicolumn{2}{|l|}{$\mathrm{K}$} & \multicolumn{2}{|l|}{$\mathrm{Ca}$} \\
\hline Base case & 27 & 0.15 & $8.0 \times 10^{-2}$ & 4 & $6.4 \times 10^{-2}$ & -12.9 & & \\
\hline Run 2 & 47 & 0.08 & $4.0 \times 10^{-2}$ & 12 & $2.8 \times 10^{-2}$ & -6.3 & & \\
\hline Run 3 & 87 & 0.05 & $2.0 \times 10^{-2}$ & 29 & $3.5 \times 10^{-2}$ & -5.2 & & \\
\hline Run 4 & 167 & 0.021 & $1.0 \times 10^{-2}$ & 115 & $3.2 \times 10^{-2}$ & -5.9 & & \\
\hline Base case & 47 & 0.3 & $4.0 \times 10^{-2}$ & 2 & & & $3.8 \times 10^{-5}$ & 0.124 \\
\hline Run 2 & 87 & 0.2 & $2.0 \times 10^{-2}$ & 5 & & & $8.0 \times 10^{-5}$ & 0.135 \\
\hline Run 3 & 167 & 0.08 & $1.0 \times 10^{-2}$ & 22 & & & $7.5 \times 10^{-5}$ & 0.042 \\
\hline Run 4 & 87 & 0.1 & $2.0 \times 10^{-2}$ & 9 & & & $6.4 \times 10^{-5}$ & 0.083 \\
\hline Run 5 & 87 & 0.05 & $2.0 \times 10^{-2}$ & 19 & & & $5.4 \times 10^{-5}$ & 0.017 \\
\hline
\end{tabular}


Table 4 Accuracy and efficiency measures for MIN3P simulations

\begin{tabular}{|c|c|c|c|c|c|c|c|}
\hline & \multirow{2}{*}{$\begin{array}{l}\text { Number } \\
\text { of cells }\end{array}$} & \multirow{2}{*}{$\begin{array}{l}\text { Max } \\
\Delta t \text { (days) }\end{array}$} & \multirow{2}{*}{$\begin{array}{l}\text { Simulation } \\
\text { time }(s)^{a}\end{array}$} & $\|x\|_{2}$ & $E_{\mathrm{F}}$ & $\|x\|_{2}{ }^{\mathrm{b}}$ & $E_{\mathrm{F}}$ \\
\hline & & & & \multicolumn{2}{|c|}{$\mathrm{K}$} & \multicolumn{2}{|c|}{$\mathrm{Ca}$} \\
\hline Base Case & 3249 & 1.0 & 257 & $1.78 \times 10^{-3}$ & -1.85 & $1.29 \times 10^{-5}$ & 0.31 \\
\hline Reduced max $\Delta t$ & 3249 & 0.1 & 1134 & $1.80 \times 10^{-3}$ & -1.91 & $1.41 \times 10^{-5}$ & 0.31 \\
\hline Increased $\max \Delta t$ & 3249 & 10.0 & 84 & $1.50 \times 10^{-3}$ & -1.30 & $7.08 \times 10^{-6}$ & 0.32 \\
\hline Fine grid & 12544 & 1.0 & 1552 & $1.73 \times 10^{-3}$ & 0.47 & $1.18 \times 10^{-5}$ & 0.36 \\
\hline Coarse grid & 784 & 1.0 & 40 & $1.22 \times 10^{-3}$ & -9.02 & $2.1 \times 10^{-4}$ & 0.16 \\
\hline
\end{tabular}

${ }^{\mathrm{a} O n}$ a Pentium(R) 2, $700 \mathrm{MHz}$, Windows XP Professional, Version 5.1, SP 2; simultaneous simulation of K, Ca, and Cl

${ }^{\mathrm{b}}$ Calculations performed for 27, 56 and 111 grid points for coarse, base case, and fine grid respectively, results normalized with respect to number of cells

weighting (Calderhead and Mayer 2004). The MIN3P simulations are run for $\mathrm{K}, \mathrm{Ca}$, and $\mathrm{Cl}$ simultaneously and simulation times increase quadratically with the number of components. Therefore, reported simulation times would be faster by a factor of roughly 9, if conducted separately for a single component (as was done for PHREEQC).

A further investigation on model accuracy of MIN3P was performed using finer and coarser discretizations in space and time (Table 4). The results suggest that the accuracy of the simulations is not sensitive to the maximum time step size. If maximum time steps are an order of magnitude larger than in the base case, the simulation time is reduced to $25 \%$ without compromising accuracy at all. Correspondingly, reducing the maximum time step size does not lead to a significant gain in accuracy, and is therefore not efficient. However, the error appears to be more sensitive to the spatial discretization.

\section{Uptake of $\mathrm{K}$ or $\mathrm{Ca}$}

All numerically simulated uptake fluxes are similar to the analytical solution, although the modeled cumulative uptake for the three codes is slightly less than for the analytical solution (Fig. 5). The uptake is calculated based on the concentration in the innermost cell, which is also prone to the highest errors. However, the overall effect on the uptake is rather small. The accuracy of the uptake flux $E_{\mathrm{F}}$ of $\mathrm{K}$ was -1.4 to $-3.3 \%$ for ORCHESTRA, -5.2 to $-12.9 \%$ for PHREEQC and 0.47 to $-9.02 \%$ for MIN3P, depending on the spatial or temporal discretization scheme. For most simulations the error was therefore less than $5 \%$. For $\mathrm{Ca}$, the simulated uptake flux was close to the analytical one, $E_{\mathrm{F}}$ for the three codes was always less than $0.4 \%$.

Both spatial and temporal discretisations have a large effect on the root uptake of Ca calculated by PHREEQC (Table 3 ). Although $E_{\mathrm{F}}$ is small for all tested runs, the simulated uptake flux
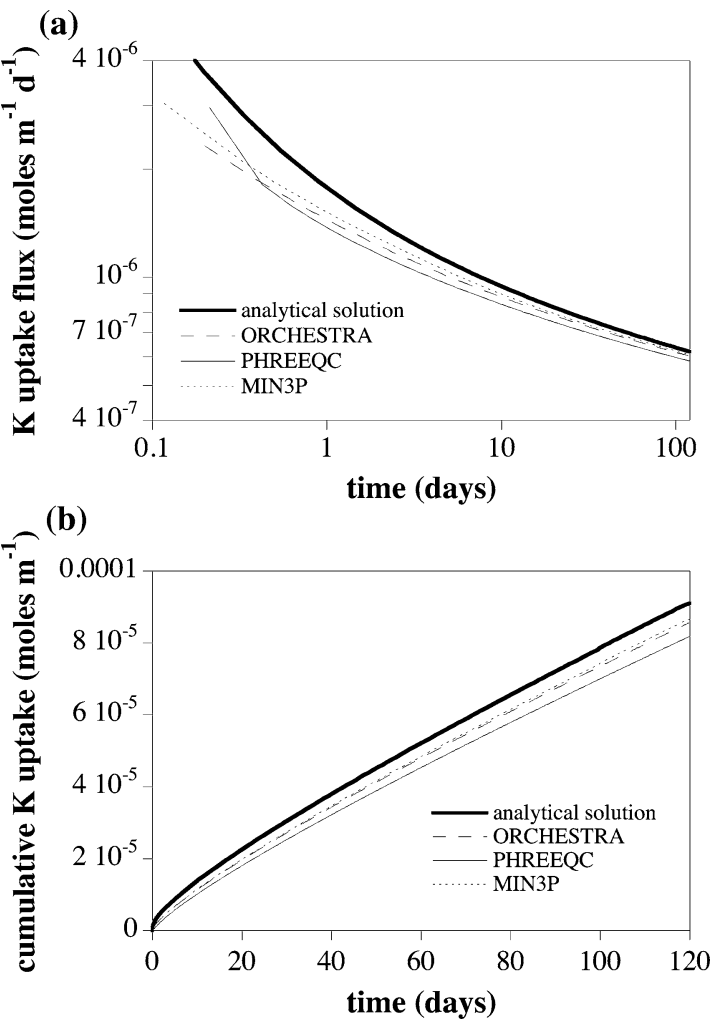

Fig. 5 Uptake of $\mathrm{K}$ by the root: (a) uptake flux as a function of time, (b) cumulative uptake. The parameters for the calculations are given in Table 1 
with PHREEQC is larger than the analytical one for coarse spatial and/or temporal discretisations. For sufficiently fine spatial discretisations $\left(\Delta r_{\mathrm{f}}=1.0 \times 10^{-2} \mathrm{~cm}\right)$ or temporal discretisations $\left(\Delta t=4320 \mathrm{~s}\right.$ for $\left.\Delta r_{\mathrm{f}}=2.0 \times 10^{-2} \mathrm{~cm}\right)$, Ca-uptake fluxes are accurately described.

It is somewhat surprising that the calculated uptake rate in MIN3P is less accurate for a refined spatial discretization (Table 4). Similar observations can be made for ORCHESTRA, where not only a finer grid results in a lower accuracy, but a coarser one results in a higher accuracy of $E_{\mathrm{F}}$, for both $\mathrm{K}$ and $\mathrm{Ca}$, and for PHREEQC where decreasing the time step did not result in better correspondence. Although the exact reason for this behavior could not be determined, for MIN3P it is likely related to the crude approximation of the root in a $2 \mathrm{D}$-cartesian coordinate

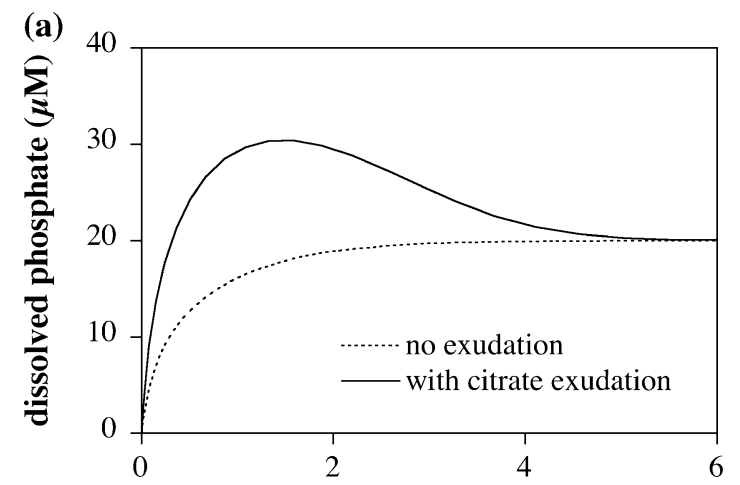

(b) distance from root surface $(\mathrm{mm})$

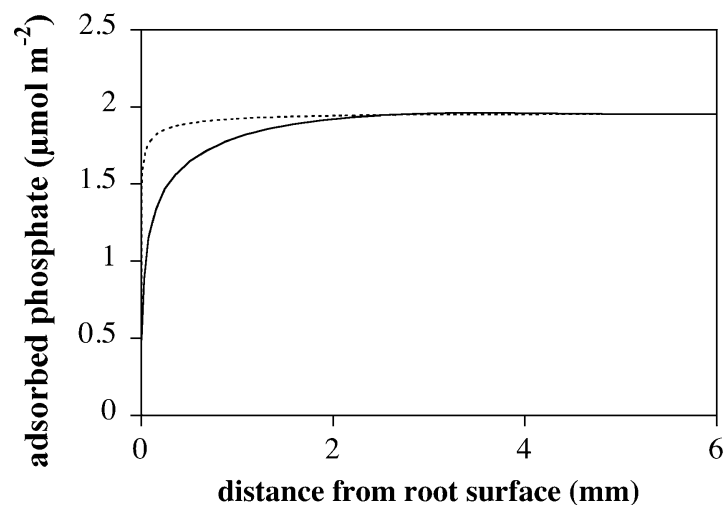

Fig. 6 Concentration profiles predicted by ORCHESTRA of (a) phosphate in solution and (b) phosphate adsorbed on goethite with and without exudation of citrate. Calculations for $95 \mathrm{~m}^{2}$ goethite per $\mathrm{kg}$ sand, $1.9 \mathrm{mmol} \mathrm{m} \mathrm{m}^{-2}$ phosphate initially bound on the goethite surface, $0.5 \mathrm{mmol} \mathrm{m}^{-1}$ day $^{-1}$ citrate exudation and $t=1$ day system. However, all simulations, even for the coarse grid, provide a reasonably good representation of the analytical solution.

Examples of applications in more realistic rhizosphere models

Figure 6 shows the phosphate concentration in the soil solution after 1 day of phosphate uptake, and the remaining bound phosphate in the soil, corresponding to Fig. 1a and b in Geelhoed et al. (1999). The simulation was repeated with and without citrate exudation. Figure 6 shows that exudation of citrate increases the concentration of phosphate in the soil solution and therefore enhances the uptake of phosphate from the soil. The concentration profiles are almost identical to those of Geelhoed et al. (1999).

MIN3P was used to simulate the problem defined in Table 1 with concurrent water uptake. The simulation results are compared to the base case without water uptake (Fig. 7). If water uptake by the root takes place, the slow MichaelisMenten-type uptake rate of $\mathrm{Ca}$ results in the build-up of $\mathrm{Ca}$ near the surface of the root, because more $\mathrm{Ca}$ is additionally transported to the root surface than is taken up there originally. This phenomenon is well known to occur in the rhizosphere (Hinsinger et al. 2005). Adding a passive uptake mechanism for $\mathrm{Ca}$ to the water uptake, results in a concentration profile very similar to

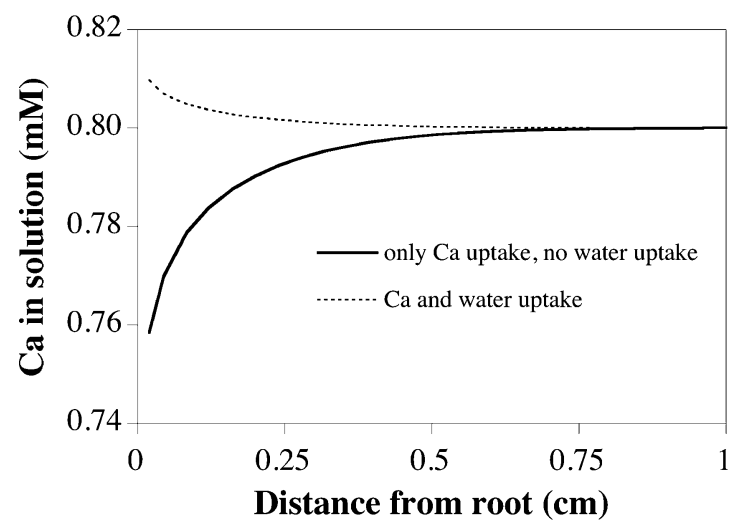

Fig. 7 Concentration profile predicted using MIN3P of specific Ca uptake by the root (according to Eq. 2) in the absence and presence of water uptake. The parameters for the calculations correspond to the ones in Table 1 with additional water uptake of $10^{-6} \mathrm{~cm}^{3} \mathrm{~cm}^{-2} \mathrm{~s}^{-1}$ 
the original one, without water uptake (data not shown).

\section{Discussion}

The good agreement between the model simulations and the analytical solution show that the three different solution strategies of the codes provide an overall equally good description of diffusion and uptake of solutes around a single root. This validation has been performed, on a strict mathematical basis, with two different solutes with different concentration in soil solution and different adsorption and uptake characteristics. Though there are model specific assumptions such as the type of grid used or replacing the Michaelis-Menten equation by an equilibrium reaction, our supposition is that the three models could henceforth be used reliably to consider additional components and increased chemical complexity.

This study demonstrates that reactive transport codes available to date are applicable in rhizosphere investigations. These codes can be used to perform studies with more complex and more detailed, and thus more realistic, soil chemistry, e.g. several species, exudation, complexation, ion exchange, aqueous redox reactions, and the degradation of organic acids among other processes. For example, it is possible to investigate the effect of exudation on acid base and redox chemistry, and the subsequent effect on mineral dissolution and precipitation in the vicinity of roots. Evidently, the choice between the three models could be driven by the particular needs, to play to the particular strengths. For example, somebody aiming for a broader community of users could use the more widespread PHREEQC; somebody wanting to include water content changes underlying the reactive transport could use MIN3P; and somebody interested in very versatile settings of boundary conditions, fluxes and chemistry could use ORCHESTRA.

This flexibility is the particular strength of the codes introduced here, lying in the fact that various combinations of biogeochemical and transport processes can now be considered simultaneously and the impact of the various parameters on the behavior of rhizosphere systems can be evaluated. We have demonstrated this in two simple additional simulations, which show the effect of citrate exudation on phosphate uptake and the effect of concurrent water uptake on solute uptake. Because the geochemical part of the three codes is well validated further inclusion of additional and more complex processes is relatively straightforward. The simulation of phosphate uptake in the presence of citrate already shows that the feedback loops between exudation and uptake can change the behavior of elements in the rhizosphere.

Future work may include the implementation of the root as a sink and source which could be improved in terms of geometry, uptake processes and including multiple roots. However, such conceptual improvements will have to be tested individually for their reliability.

A significant step towards the application of multicomponent reactive transport codes in the rhizosphere has been achieved in the work presented here. The accuracy demonstrated, and the existing verification of these codes for transport and geochemical simulations, is a promising basis for rhizosphere scientists to quantitatively test their conceptual models resulting from interpretation of experimental data to numerical simulations accounting for non-linear interactions.

Acknowledgements This work profited from meetings and courses funded by the European Union within the framework of COST action 631 "Understanding and modeling plant-soil interactions in the rhizosphere environment". The presented work is a collaborative effort of the working group "Models and databases of the rhizosphere including data transformation". We would like to thank two anonymous reviewers for their comments that helped to improve the paper significantly.

\section{References}

Allison JD, Brown DS, Novo-Gradac KJ (1991) MINTEQA2/PRODEFA2. A geochemical assessment model for environmental systems. Version 3.0, U.S. Environmental Protection Agency, Washington, DC, available at http://www.epa.gov/ceampubl/mmedia/minteq/index.htm

Appelo CAJ, Postma J (2005) Geochemistry, groundwater and pollution. A.A. Balkema, Leiden, pp 649 
Barber SA (1995) Soil nutrient bioavailability: a mechanistic approach, 2nd edn. John Wiley \& Sons, New York

Calba H, Cazevieille P, Jaillard B (1999) Modeling of the dynamics of $\mathrm{Al}$ and protons in the rhizosphere of maize cultivated in acid substrate. Plant Soil 209:57-69

Calba H, Firdaus, Cazevieille P, Thée C, Poss R, Jaillard B (2004) The dynamics of protons, aluminum, and calcium in the rhizosphere of maize cultivated in tropical acid soils: experimental study and modelling. Plant Soil 260:33-46

Calderhead A, Mayer KU (2004) Comparison of the suitability of the global implicit method and the sequential non-iterative approach for multicomponent reactive transport modelling. In: Proceedings of 5th Joint IAH-CNC/CGS Conference, Québec City, Québec, Canada, October 24-28, Session 6A:32-39

Geelhoed JS, Van Riemsdijk WH, Findenegg GR (1999) Simulation of the effect of citrate exudation from roots on the plant availability of phosphate adsorbed on goethite. Eur J Soil Sci 50:379-390

Gérard F, Tinsley M, Mayer KU (2004) Preferential flow revealed by hydrologic modeling based on predicted hydraulic properties. Soil Sci Soc Am J 68:1526-1538

Hiemstra T, Van Riemsdijk WH (1996) A surface structural approach to ion adsorption: the charge distribution (CD) model. J Colloid Interface Sci 179:488508

Hiltner L (1904) Über neue Erfahrungen und Probleme auf dem Gebiet der Bodenbakteriologie unter besonderer Berücksichtigung der Gründüngung und Brache. Arb Dtsch Landwirt Gesellschaft 98: 59- 78

Hinch EJ (1991) Perturbation methods. Cambridge University Press

Hinsinger P, Gobran GR, Gregory PJ, Wenzel WW (2005) Rhizosphere geometry and heterogeneity arising from root-mediated physical and chemical processes. New Phytol 168:293-303

Jacques D, Simunek J (2005) User manual of the multicomponent, variably-saturated flow and transport model HP1. Description, verification and Examples, Version 1.0. SCK·CEN, Belgium, SCK·CEN, BLG988, $79 \mathrm{p}$

Keizer MG, van Riemsdijk WH (1995) ECOSAT, a computer program for the calculation of chemical speciation and transport in soil-water systems. Wageningen Agricultural University

Kirk GJD (1999) A model of phosphate solubilization by organic anion excretion from plant roots. Eur J Soil Sci 50:369-378
Mayer KU, Frind EO, Blowes DW (2002) Multicomponent reactive transport modeling in variably saturated porous media using a generalized formulation for kinetically controlled reactions. Water Resour Res 38:1174-1194

Meeussen JCL (2003) ORCHESTRA: an object-oriented framework for implementing chemical equilibrium models. Environ Sci Technol 37:1175-1182

Parker DR, Pedler JF (1997) Reevaluating the free-ion activity model of trace metal availability to higher plants. Plant Soil 196:223-228

Parkhurst DL, Appelo CAJ (1999) User's guide to PHREEQC (version 2). A computer program for speciation, batch-reaction, one-dimensional transport, and inverse geochemical calculations. In: Water resources investigations report 99-4259. US Geological Survey, $312 \mathrm{pp}$

Roose T (2000) Mathematical model of plant nutrient uptake. Thesis, DPhil. Oxford University

Roose T, Fowler AC, Darrah PR (2001) A mathematical model of plant nutrient uptake. J Math Biol 42:347-360

Seuntjens P, Nowack B, Schulin R (2004) Root-zone modeling of heavy metal uptake and leaching in the presence of organic ligands. Plant Soil 265:61-73

Silberbush M, ben-Asher J, Ephrat JE (2005) A model for nutrient and water flow and their uptake by plants grown in a soilless culture. Plant Soil 271:309-319

Simunek J, Senja M, van Genuchten MT (1998) The HYDRUS-1D software package for simulating the one-dimensional movement of water, heat, and multiple solutes in variably-saturated media. Version 2.0. IGWMC-TPS-70. International Ground Water Modeling Center, Colorado School of Mines, CO, $202 \mathrm{p}$

Steefel CI, MacQuarrie KTB (1996) Approaches to modeling of reactive transport in porous media. Rev Mineral 34:83-129

Tinker PB, Nye PH (2000) Solute movement in the rhizosphere. Oxford University Press, New York

Unger AJA, Forsyth PA, Sudicky EA (1996) Variable spatial and temporal weighting schemes for use in multi-phase compositional problems. Adv Water Resour 19:1-27

Westall JC, Zachara JL, Morel FMM (1972) MINEQL, a computer program for the calculation of the chemical equilibrium composition of aqueous systems. Department of Civil Engineering, Massachusetts Institute of Technology Technical Note No. 18

Yeh GT, Tripathi VS (1989) A critical evaluation of recent developments in hydrogeochemical transport models of reactive multichemical components. Water Resour Res 25:93-108 